\title{
Temperature regulation and technology
}

\author{
George Havenith PhD \\ Department of Human Sciences, Human Thermal Environments Laboratory, \\ Loughborough University, Loughborough, United Kingdom, LE11 3TU \\ e-mail: G.Havenith@lboro.ac.uk
}

\begin{abstract}
G. Havenith, Temperature regulation and technology, Gerontechnology, 2001; 1(1): 41 - 49. The ability to thermoregulate typically decreases with age. This is strongly related to decreases in physical fitness and increases in the incidence of disabilities with ageing. The reduced thermoregulatory capacity leads to increased mortality and morbidity. Heat stroke, hypothermia, increased number of falls, and in home drowning are some of the problems that are identified to be associated with this reduced thermoregulatory capacity. As solution, using advanced technology in terms of full climate control is suggested as a short-term solution for the ill or infirm only. For longer-term solutions, limited climate control (taking away peak loads), improved housing design and proper use of modern clothing are proposed to alleviate the problems. For the clothing, better education of the elderly in the possible advantages of high tech clothing materials is proposed, as well as education to their proper way of use. Manufacturers should consider adjusting their marketing policies to include the elderly in their targeted groups.
\end{abstract}

Key words: temperature regulation, ageing, thermal comfort, mortality, morbidity

With advancing age our ability to thermoregulate tends to decrease ${ }^{1,2,3}$ This is a multi-factorial process involving many of our physiological systems with an emphasis on the cardiovascular system. The most important factor is that physical fitness tends to decrease with age ${ }^{1,4}$ mostly due to a reduced physical activity level in the elderly 5 . This implies that any activity performed becomes more stressful with advancing age. It will put more strain on the cardiovascular system, and leave less cardiovascular reserve. The cardiovascular reserve is especially relevant to the capacity for thermoregulation as it determines the capacity to move heat for dissipation from the body core to the skin by the skin blood flow. The fitness reduction can work like a vicious circle as the increased strain experienced with activity may in itself promote even further activity reduction. Due to a reduced activity, people also tend to expose themselves less to physical strain in the form of heat or cold exposure. This leads to a loss of heat and cold acclimatisation ${ }^{6}$, which will result in higher strain when the elderly are on occasion exposed to extreme climates. Typically on a population level these and other changes lead to a reduced muscle strength, reduced work capacity, a reduced sweating capacity, a reduced ability to transport heat from the body core to the skin, reduced hydration levels, reduced vascularreactivity and a lower cardiovascular stability (blood pressure) in the elderly. These effects will put elderly people at a higher risk in extreme conditions, leading to an increase in morbidity and mortality.

Apart from the physiological changes mentioned above, the percentage of people with illnesses and disabilities increases with age as well. In the UK $41 \%$ of people aged $65-74$ and $52 \%$ over 75 reported that their lifestyle was limited by an illness or disability, compared to $22 \%$ of all age group 7 . This also has consequences for well-being in various thermal environments. Drug use associated with illness often has a negative effect on thermoregulation too. 


\section{MORTALITY AND MORBIDITY}

In order to provide an overview of the problems related to ageing and temperature regulation, we will now discuss those aspects of mortality and morbidity that in the past have been associated with high or low temperatures. The main ones are heat stroke, hypothermia, cardiovascular and cerebral stroke, and in-home accidents as falls and bathing accidents.

Statistical evidence from heat waves in American and Japanese cities shows that mortality increases dramatically with age when temperature increases. Figure 1 shows data on the number of deaths due to heat stroke mortality by age group for the period of 1968 through 1994 in Japan ${ }^{8}$. It is evident that there is a sharp increase in mortality due to heat above the 6 th decade. The peak daily temperatures when these heat strokes occurred were typically above $38{ }^{\circ} \mathrm{C}$, although a relatively increased mortality in the elderly compared to younger groups has also been observed at lower temperatures. Data from the United States provide a similar

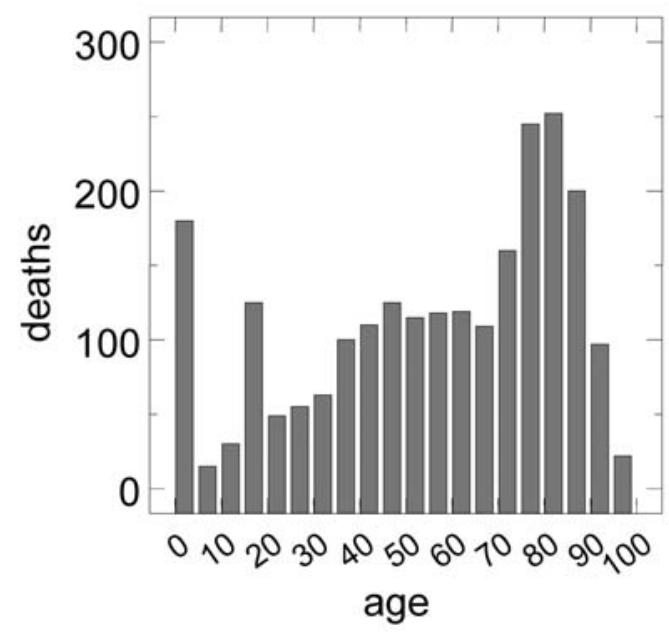

Figure 1. Heat stroke mortality by age group from 1968 to 1994 in Japan. Data from Nakai et al ${ }^{8}$ picture, with typically above $60 \%$ of heat related deaths during heat waves above the 6 th decade of age. While heat stroke deaths among those aged below 64 years were typically exertion induced heat strokes (outdoor sports or occupational hazards), this was not the case in the elderly. As mentioned in the introduction, they have a very limited cardiovascular reserve, reduced hydration levels ${ }^{9}$, and a reduced sweating capacity, all putting them at higher risk to develop hyperthermia. Apart from heat stroke, the high cardiovascular strain may also set them up for cardiovascular or cerebral stroke.

The analysis of mortality and morbidity data for cold exposure is more complex ${ }^{10}$, as many cold related problems may not be attributed to the cold in statistics. Only extreme hypothermia cases may be registered as such, but mild hypothermia and in general excursions into the cold can have a severe impact on health too. Suggested causes are the induced haemoconcentration and the raised blood pressure ${ }^{1,11,12}$ which could put additional strain on the cardiovascular system and which may set the elderly up once more for cardiovascular or cerebral stroke.

Another problem in the elderly is the incidence of falls. The number of falls increases dramatically with age as can be seen in Figure 2. At the age of 84 , the number of falls is over 60 percent higher than at the age of 65, while the size of this age group is much smaller than that of 65 . There is no clear statistical evidence that these falls are related to temperature however. This lack of statistical significance is most likely due to the large number of confounding factors involved in these falls and in the way they are registered in databases. A causal relation with cold as one of the contributing factors to falls is however likely, given that cold reduces muscle force, and increases stiffness of joints and tendons ${ }^{13}$. Hence, in the elderly where fitness and muscle force are already reduced cold, even mild indoor cold, will aggravate these problems. Further, people 
will wear more clothing in the cold, increasing the clothing stiffness and thus decreasing the freedom of movement ${ }^{14}$.

A special case of accidents in the home is observed in Japan. Analysing death rates due to home accidents in Japan, as in other countries, falls represent a high percentage of the overall causes of accidental death at home. However, in Japan this number is even superseded by drowning as cause of home accidents. Data published by the Ministry of welfare $^{15}$ showed that drowning is listed as cause of accidental death in the home in $26 \%$ of the cases compared to $23 \%$ for falls. It was shown that death rate was directly related to the time of year, especially in older adults. In the winter season the rate increases dramatically as can be seen in Figure 3, with the majority of these deaths occurring in the bathroom ${ }^{16}$. Ohnaka ${ }^{17}$ investigated the indoor climatic circumstances in Japanese cities, especially those with a warm summer climate for a full year period. In winter he observed extreme temperature differences

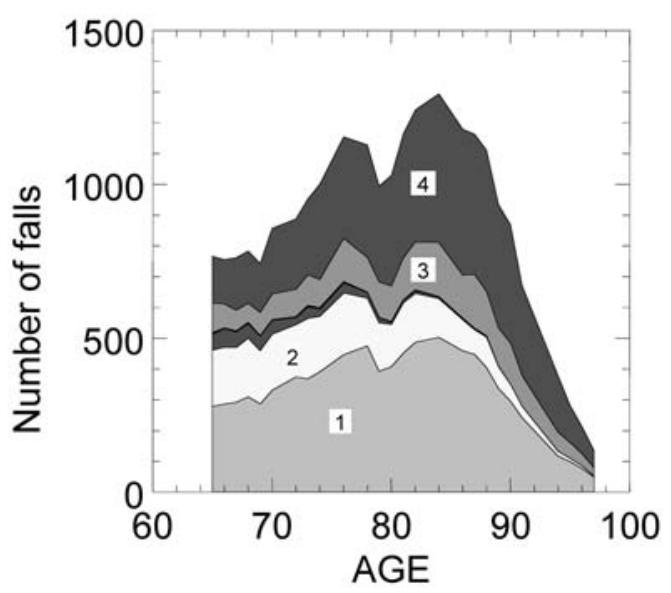

Figure 2. Number of falls in selected UK area; $1=$ slip/trip/tumble;

2=stairs/steps;

3=level;

4=unspecified. between living room and bathroom in many houses in these areas. He attributes this to the building style, which is mainly geared towards the summer season. During cool winters, bathroom temperatures were on average around $15^{\circ} \mathrm{C}$ compared to $30^{\circ} \mathrm{C}$ in the summer. With the bath temperatures around $42^{\circ} \mathrm{C}$ in the winter, it is obvious that between undressing and actually entering the bath the body experiences substantial climate induced cardiovascular stress. Compared to European and American circumstances $^{16,17}$, bathrooms are colder, water temperature is higher and bathtubs are deeper in Japan. It is hypothesised, that the extreme temperature gradients cause cardiovascular instability, aggravated by the elderly's reduced vascular reactivity and more pronounced blood pressure response ${ }^{16,17}$, leading to loss of consciousness, and finally to drowning in the bath.

\section{COMFORT}

While the previous section dealt with possible life-threatening conditions related to temperature regulation, another important topic in this area is thermal comfort. In the design of houses, or of institutions, the performance of the building in terms of comfort is an integral part of the design process ${ }^{18}$. Climatic control equipment is selected such that comfort conditions within the building can be guaranteed for most of the year. In this light it is obviously important to consider the effects of ageing on comfort sensation. Various studies have shown that in principle the elderly do not perceive comfort differently from younger groups, when clothing, metabolic rate, body characteristics, and ambient temperature are taken into account ${ }^{19}$. However the elderly on average have a lower activity level, which implies a lower metabolic heat production ${ }^{19,20,21}$ and thus the need for a higher ambient temperature for comfort compared to younger groups. Also (cultural) differences in clothing worn may create differences in comfort requirements between the older and younger groups. 
With advancing age, morbidity in the population will increase. The number of people with physical disabilities increases, influencing typical activity patterns and thereby affecting comfort. Research by Webb et $\mathrm{a}^{22}$ on 140 people with different disabilities indicated that at thermoneutral temperatures the average comfort vote was the same as for non-disabled people. Strikingly however the variance in the votes was much larger for the disabled (Figure 4). When the climate was slightly cool or slightly warm, disabled people rated their discomfort more extreme compared to the non-disabled though all this was not significant possibly due to the high variance in disabilities. A significantly higher rate of people dissatisfied with the climate was observed compared to the expectations however. It is assumed that due to their limited capacity for adaptation to the environment (clothing or activity change, leaving the area), the disabled group reacted stronger to deviations from the comfort zone.

\section{THE ROLE OF TECHNOLOGY}

After this overview of problems related to temperature regulation and the elderly, we now need to analyse these problems and

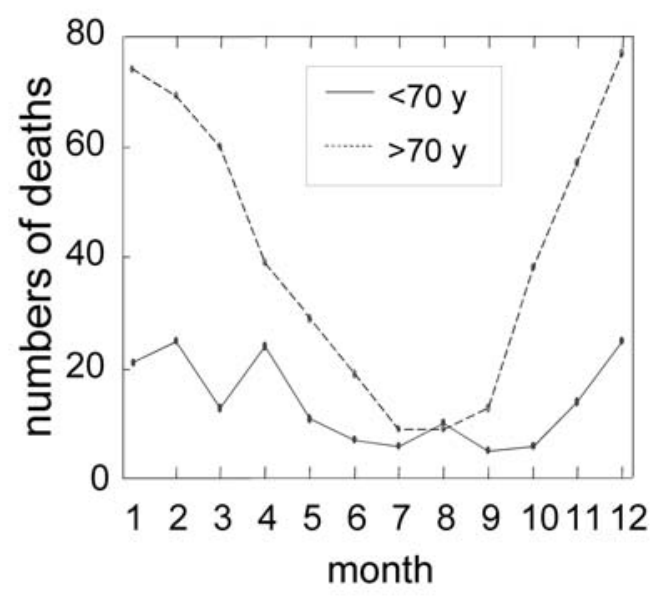

Figure 3. Number of deaths in baths for Tokio ${ }^{16}$, 1988, 1989. define the ways in which technology can be used to alleviate them.

Of all mentioned problems, obviously mortality is most important. Summer and winter mortality related to climate, can for a large part be attributed to exposure to very high or low temperatures respectively ${ }^{10}$. Another part seems due to more moderate changes in temperature, i.e. excursions in to the heat or cold, and even the indoor temperature was suggested to contribute ${ }^{3,23}$.

\section{Controlled Environments}

Should this be solved by placing the elderly in a strictly climate controlled enclosure? Though this would reduce mortality during climatic extremes, it would also take away all the natural stimuli, which normally induce acclimatisation to cold or heat and are beneficial in preventing climate-related illnesses ${ }^{6}$. Only in cases were ill health is present such drastic measures should be taken as a shortterm protection. For otherwise healthy people, it seems advisable to protect them from climatic extremes and to provide a comfortable indoor environment ${ }^{3,23}$, but not to take away the normal stimuli in order not to compromise long-term protection. An active lifestyle (fitness) with climatic exposure but with proper adjustment to the climate (behaviour, clothing) should keep natural acclimatisation levels at beneficial levels. In the design of houses protection against extremes could be realised with active heating or cooling systems but considering the energy requirements and the higher occurrence of a low socio-economic status in the elderly a passive system may be preferable. The main goal would be to dampen the fluctuations in environmental temperature, which can be achieved by using high heat capacity buildings in combination with control of solar penetration. Outdoor protection can be improved by proper behaviour, clothing and shelter from extreme exposures (e.g. protection from rain and wind in bus shelters). 
In the design of heating systems many countries' building regulations suggest a different design temperature for different areas of the house i.e. lower temperatures for the bedroom, around $21^{\circ} \mathrm{C}$ in the living room and $22^{\circ} \mathrm{C}$ to $24^{\circ} \mathrm{C}$ for the bathroom. These temperatures are based on the different activities and clothing levels in the various areas of the house. With the elderly being less active, one could raise all these values by small amount. For elderly with an illness or a disability, one may choose to keep the temperatures closer together as they will not be able to change activity or clothing level as required for these temperature differentiations. For healthy people however some variation should exist. Though no scientific basis is present to suggest thermal boredom, the variation in temperature should stimulate the thermal system in a positive way ${ }^{24}$.

For the heating season, one may argue in favour of floor heating systems. Peripheral vascular reactivity decreases with age $\mathrm{e}^{25}$, leading to more perfused extremities with high heat loss. This could be counteracted by such heating systems.

With advancing technology it is now possible to provide building occupants with localised temperature control, which is useful to adapt for instance office or residential care institution's climates to the individual requirements $^{24}$. In these systems the room as a whole may be controlled for the 'average' occupant, while the individual has controls to alter local air speed (vents/fans), or can locally introduce heated or cooled air. For the home, and especially for ill or disabled people with reduced mobility, remote control of the temperature regulator should be considered. This will allow them to adjust the climate to their personal preference of the moment without being dependent on a carer's intervention.

It should be emphasised here that air temperature is not the only climatic parameter that is relevant in terms of control. Radiation was already mentioned, and humidity should be considered as well. Relative humidity and temperature together will determine the ambient vapour pressure, which defines the evaporative capacity in a certain climate. With the elderly having a reduced sweating capacity, it is essential that the sweat they produce can be evaporated. Most climate control systems that cool air will automatical-

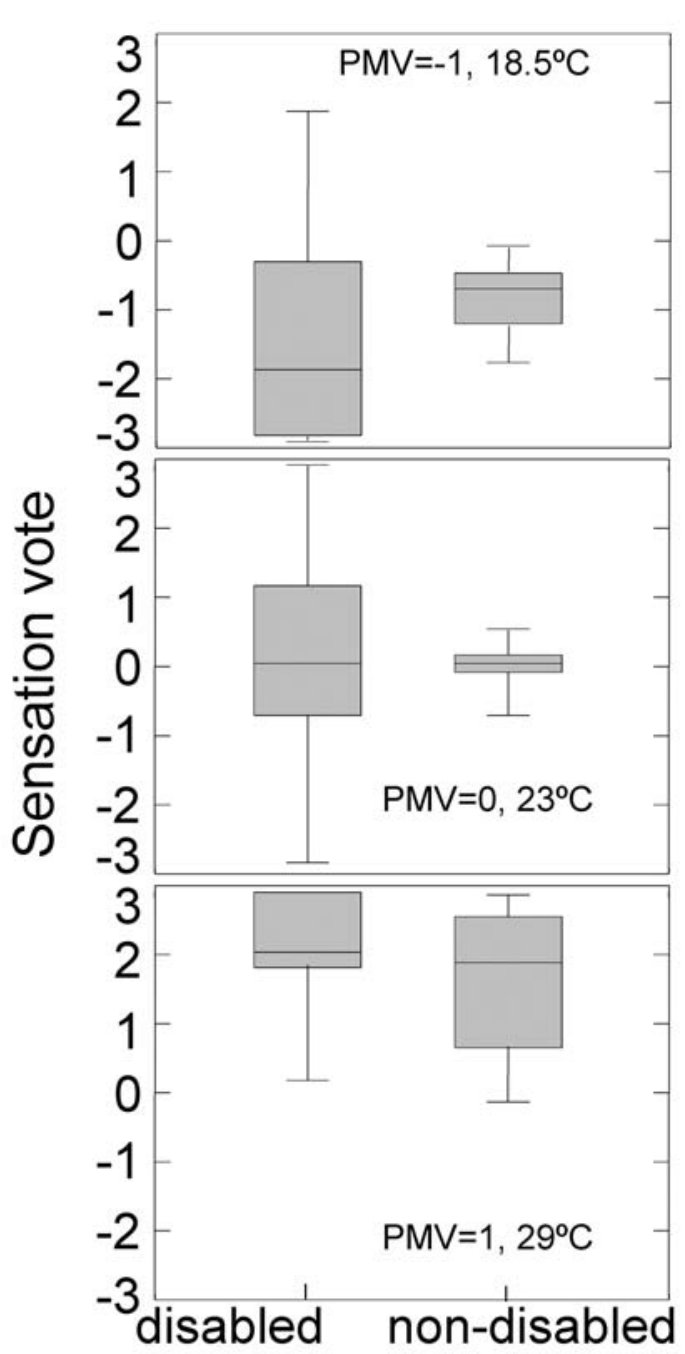

45

Figure 4. Temperature sensation for disabled $(n=113)$ and able bodied $(n=16)$ subjects; $0=$ neutral, $3=$ hot, $-3=$ cold; redrawn from data of Webb et al22 
ly cause a reduced relative humidity and take care of this problem in the heat. In cold conditions often low relative humidities are observed indoors. Though no direct health risk seems associated with low humidities, dry air may cause discomfort for users of contact lenses as well as for people with skin or respiratory tract problems. A general guideline to keep relative humidity between 30 and $70 \%$ is often found in literature. The upper relative humidity limit is related to air quality issues, as mould growth and transport.

When controlling temperature, especially in the cold season, care should be taken that sufficient ventilation is present. Those elderly living on their own often do so in older homes with older heating systems. While trying to reduce heat loss through ventilation in order to save energy and thus money, they run the risk of carbon monoxide poisoning. Also in absence of the risk of carbon monoxide poisoning ventilation is of importance to maintain air quality. Lower air quality coincides with higher numbers of pathogens in the air, especially at high humidities. Usually Carbon Dioxide $\left(\mathrm{CO}_{2}\right)$ concentration is used as indicator for air quality. Apart from the higher susceptibility of the elderly to disease, air quality requirements are not different from the general population.

A positive development in this respect is the increased number of houses that are equipped with forced or natural ventilation systems, which can be regulated by the inhabitants. This increases air quality and reduces energy cost when compared to air conditioning systems or uncontrolled ventilation.

\section{High Tech Clothing}

The above section mainly discusses adjustments of the environment of which some may be costly to implement and could have a negative impact on the environment (energy use). An often cheaper and more direct way to influence thermal comfort and well- being is the optimisation of the clothing worn. When visiting old people's homes one often sees them wearing traditional clothing with only a limited variation between summer and winter. The first step to improve this would be to educate the elderly about the effects of clothing on their thermal comfort and on their susceptibility to heat or cold illnesses. Encouraging the elderly to adjust the clothing to the circumstances, especially during excursions outside the comfort envelope, can be a first step towards their climatic awareness and thereby reducing risk.

In terms of clothing materials a large number of technological innovations have been put on the market. In terms of their function they can be grouped as:

- Insulative materials

- Moisture transport materials

- Breathable, rain protection materials

- Phase change materials

- Smart materials

Insulative materials:

Though no real 'miracle' materials have reached the market ${ }^{14}$, despite advertising claims to that effect, remarkable progress has been made in the quality of insulating garments ${ }^{14}$. In order to protect the elderly from extreme climate changes (cold) that may trigger cardio- or cerebrovascular problems, a good protection from the climate is essential. The first defence is proper adjustment of clothing to the climate. Adjustments are usually easiest if they can be made to the outermost layer. Adding or changing one of the permanent layers can achieve a general change of the 'comfort' range. Most new materials have concentrated on the underwear layer. Mainly in the application of outdoor leisure, new materials are marketed that provide a good insulation in combination with good wearability and comfort. The insulation for weight ratio has been improved by using hollow and thinner fibres. For a given material weight this reduces radiant heat transport and thereby improves insulation. Typically, man made fibres have 
replaced natural fibres. Though insulation of natural fibres can certainly compete with the man made ones, their moisture absorption is usually too high and can negatively influence comfort.

Most of these modern 'next to skin' materials also have improved moisture transport capacities.

\section{Moisture transport materials:}

One if the problems with insulative materials is that they may be too insulative in periods of higher activity. This leads to sweating, and sweat can accumulate in the clothing. When the activity ends, metabolic heat production is reduced, but evaporation of the moisture continues. This leads to the so-called 'after chill', which would have a greater health impact in the elderly due to their reduced thermal sensitivity and cardiovascular reactivity. To prevent this, materials have been developed to take moisture away from the skin by wicking and to transport it to the outer surface of the garment from where it will evaporate. This, together with lower moisture absorption, reduces the risk of after chill. Technically, this is achieved by producing a double layer garment with wicking materials on the inside and absorbing materials on the outside, or more generally to use fibres or finishes for the garment that wick moisture along the fibre surface quickly.

\section{Breathable rain protection materials:}

When going outdoors it is important to protect the elderly from getting wet clothing, as this will increase heat loss dramatically and could induce health problems. Outdoors, the first protection for this is that against rain. However, a problem with rain protection (coatings, membranes) is that it reduces the breathability of garments, and often causes the garments closer to the skin to become wetted from the inside, by sweat. This problem can be reduced by using modern, waterproof but 'breathable', garments. These allow a certain amount of moisture to evaporate, even in wet conditions ${ }^{14}$ and reduce the total accumulation of moisture.
Phase change materials:

Very recently a new group of materials has been introduced: phase change materials. These materials contain a large number of microscopic capsules containing substances that change phase (solid to liquid and vice versa) at a predefined temperature. In this process they either absorb or liberate heat, which works as a buffer to keep external heat or cold away from the wearer. These materials can protect the elderly during short excursions from their home outdoors during cold or hot spells. Unfortunately the total buffering capacity of these materials is still very limited, as is their overall effect ${ }^{26}$. However they seem promising for further development and may be seen as a step towards 'smart clothing'

\section{Smart materials:}

The idea for smart clothing/smart materials is that the clothing properties would automatically adjust to the needs of the wearer. These needs would be defined in terms of the climate and the activity level. Though it may be difficult to create clothing with an adjustable waterproofness-breathability balance, indeed prototype materials are now available that can change their insulation depending on the temperature ${ }^{27}$. They do this by changing thickness with temperature. In that way, the insulation increases with decreasing temperature. The next step is to incorporate an adjustment based on the wearer's activity level (metabolic heat production), as this is at least as important an input as the ambient temperature.

Most of the materials above are considered high tech materials and originate from military or outdoors leisure and sport applications. They are often expensive, which limits the availability for the elderly population. Further, despite the potential benefits for the elderly populations, they are marketed towards the 'young and active'. Marketing towards the elderly may be seen by the producers as counter productive in relation to the younger markets. Education of the elder- 
ly as to the possible benefits and correct use of such clothing is therefore imperative to gain acceptance. These clothing innovations provide both a good short-term protection (excursions into the cold) as well as a longerterm protection (reduced exposure).

\section{CONCLUSIONS}

Mortality and morbidity related to climatic stress can be reduced with modern technology. Sophisticated climate control may seem the obvious choice, but could enter the building's occupants in a vicious circle. Further development of clothing materials and education on proper clothing use could help to reduce climate-related problems in the elderly too.

\section{References}

1. Havenith $G$, Inoue $Y$, Luttikholt $V$, Kenney WL. Age predicts cardiovascular, but not thermoregulatory, responses to humid heat stress. Eur J Appl Physiol 1995 70:88-96.

2. Inoue $Y$, Havenith $G$, Kenney $W L$, Loomis JL, Buskirk ER. Exercise- and methylcholineinduced sweating responses in older and younger men: effect of heat acclimation and aerobic fitness. Int. J. Biometeor. 1999, 42, Iss 4: 210-216.

3. Keatinge WR, Donaldson GC, Bucher K, Jendritsky G, Cordioli E, Martinelli $M$, Dardanoni L, Katsouyanni K, Kunst AE, Mackenbach JP, McDonald C, Nayha S, Vuori I. Cold exposure and winter mortality from ischaemic heart disease, cerebrovascular disease, respiratory disease, and all causes in warm and cold regions of Europe Lancet 1997, 349 (9062): 1341-1346.

4. Åstrand PO, Rodahl K. Textbook of work physiology; McGraw-Hill publ New York 1970

5. DTI. Home accidents surveillance system, including leisure activities. HASS 22nd annual report 1999.

6. Havenith $\mathrm{G}$. Individual differences in thermoregulation; a review. Report of TNOInstitute for Perception 1985-C26, 1985.

7. DTI. Avoiding slips, trips and broken hips; older people in the population. Fact sheet department of trade and industry 1998.

8. Nakai $S$, Itoh T, Morimoto $T$. Deaths from heat stroke in Japan: 1968-1994. Int.J.

Biometeorol. 1999, 43:124-127.
9. Collins KJ, Cowen T. Disorders of the autonomic nervous system. In: Geriatric Medicine and Gerontology, 5th edition, Tallis, Fillit and Brocklehurst eds. Churchill Livingstone, Edinburgh 1995.

10. Jendritzky G, Bucher K, Laschewski G, Walther $\mathrm{H}$. Atmospheric heat exchange of the human being, bioclimate assessments, mortality and thermal stress. Int. J. of Circumpolar Health, 2000, 59: 222-227.

11. Neild PJ, Syndercombecourt D, Keatinge WR, Donaldson GC, Mattock M, Caunce M. Cold-Induced Increases In Erythrocyte Count, Plasma-Cholesterol And Plasma-Fibrinogen Of Elderly People Without A Comparable Rise In Protein-C Or Factor-X, Clinical Science 1994, 86 (1): 43-48.

12. Donaldson GC, Robinson D, Allaway SL. An analysis of arterial disease mortality and BUPA health screening in men, in relation to outdoor temperature. Clinical Science. 1997, 92:261-268.

13. Havenith $G$, Heus $R$,. Daanen HAM. The hand in the cold, performance and risk. Arctic med. research, 1995, 54, suppl.2: 1-11.

14. Havenith G. Heat Balance When Wearing Protective Clothing', Annals of Occup. Hygiene, 1999 43(5): 289-296.

15. Ministry of health and welfare. Statistics of the population in Japan, 1993, p300

16. Tochihara Y. Bathing in Japan, a review. Journal of the Human Environment System, 1999, 3(1) 27-34.

17. Ohnaka T. Thermal conditions in the bathrooms of the elderly in summer, autumn and winter in Japan. In: Environmental Ergonomics VIII, 1999, ISBN 0-9666953-1-3: 359-362.

18. McCartney K, Nicol F. Moving thermal comfort standards into the 21st century. Proceedings of the Windsor conference 2001.

19. Cena K, Spotila JR, Ryan EB. Effect of behavioral strategies and activity on thermal comfort of the elderly, AHSRAE transactions 1988 vol 94, pt 1:311- 460.

20. Goodwin J, Taylor RS, Pearce VR, Read KLQ. Seasonal cold, excursional behaviour, clothing protection and physical activity in young and old subjects. Int. J. Circ. Health, 2000, 59, 4: 195-203.

21. Tsuzuki K, Ohfuku T, Iwata T, Mizuno K., Thermal comfort for the elderly people, Proceedings of International Workshop on Gerontechnology, Age-Related Change in Human Factors and Application Technology, 2001 Tsukuba, March 13-16.

22. Webb LH, Parsons KC, Hodder SG. Thermal 


\section{Temperature Regulation}

comfort requirements: a study of people with multiple sclerosis. ASHRAE Transactions 1999 SE-99-5-2: 648-659.

23. Keatinge WR, Donaldson GC, Cordioli EA, Martinelli $M$, Kunst AE, Mackenbach JP, Nayha S, Vuori I. Heat related mortality in warm and cold regions of Europe: observational study British Medical Journal 2000, 321 (7262): 670-673.

24. Brager GS, de Dear R. Climate, comfort and natural ventilation: a new adaptive comfort standard for ASHRAE standard 55. In: moving thermal comfort standards into the 21st century. Proceedings of the Windsor conference 2001, McCartney, K. and Nicol, F. eds.

25. Kenney WL, Havenith G. Heat stress and age: skin blood flow and body temperature. J Therm Biol 1993, 18 (5/6):341-344.

26. Shim $\mathrm{H}$, McCullough EA. The effectiveness of phase change materials in outdoor clothing. Ergonomics of protective clothing, Arbete Och Hälsa, 2000:8, p 90-97.

27. Scott RA. Fibres, Textiles and Materials for future military protective clothing, Ergonomics of protective clothing, Arbete Och Hälsa, 2000:8, p 108-113. 